\title{
RELAÇÃO PODER-SABER E FORMAS DE RESISTÊNCIA EM DOCUMENTOS EDUCACIONAIS GOVERNAMENTAIS SOBRE ENSINO DE LÍNGUA ESTRANGEIRA
}

\author{
Sandra Mari Kaneko MARQUES*
}

- RESUMO: Considerando o discurso político-educacional como meio de manifestação de poder, este artigo tem como objetivo propor reflexões acerca da relação poder-saber em documentos educacionais de diferentes esferas governamentais, nos quais se apresentam eventuais formas de resistência. Para verificar como se dá essa relação, serão analisadas as Orientações Curriculares para o Ensino Médio: Linguagens, Códigos e suas Tecnologias, documento elaborado pela Secretaria de Educação Básica (SEB) e a Proposta Curricular do Estado de São Paulo: Língua Estrangeira Moderna - Inglês, da Secretaria da Educação de São Paulo (SEE), publicadas em 2006 e 2008, respectivamente. Para tanto, o arcabouço teórico será embasado em conceitos sobre a relação poder-saber, formas de resistência e regimes de verdade amplamente discutidos por Foucault (1971, 2008), Pêcheux (1990), Mascia (2002), Bertoldo (2003), Coracini (2003), Gregolin (2004), Orlandi (2006), Veiga-Neto (2007), Possenti (2007) e Amarante (2009). Por meio da análise desses documentos, notou-se a presença de traços argumentativos que contribuem para o estabelecimento de um regime de verdade, perpassado por relações de poder-saber. Além disso, os resultados obtidos apontam para polêmicas existentes entre as Orientações Curriculares Nacionais e a Proposta Curricular do Estado de São Paulo no que concerne aos pressupostos teóricos e orientações práticas para o ensino e aprendizagem de línguas.

- PALAVRAS-CHAVE: Ensino. Língua estrangeira. Poder-saber. Discurso político-educacional.

\section{Introdução}

O Discurso Político-Educacional (doravante DPE) é considerado por alguns autores (MASCIA, 2002) como educacional, pois seu objeto é a educação e o saber por ele veiculado, assim como também é político, pois se estabelece por instâncias nas quais estão delegados os poderes e as autoridades sobre a educação. Dessa maneira, o DPE pode ser considerado um meio de manifestação da relação poder-saber, presente em documentos curriculares oficiais que regulamentam as práticas educacionais no Brasil.

\footnotetext{
* UNESP - Universidade Estadual Paulista. Faculdade de Ciências e Letras. Araraquara - SP - Brasil. 14800-901 - sandrak@fclar.unesp.br
} 
Com base em tais manifestações, este artigo tem como objetivo levantar algumas asserções acerca da relação poder-saber e das formas de resistência em dois documentos de diferentes esferas governamentais. Na tentativa de verificar como se dá essa relação, serão analisadas as Orientações Curriculares para o Ensino Médio: Linguagens, Códigos e suas Tecnologias, documento elaborado pela Secretaria de Educação Básica (SEB) e a Proposta Curricular do Estado de São Paulo: Língua Estrangeira Moderna - Inglês, da Secretaria da Educação de São Paulo (SEE), publicadas em 2006 e 2008.

Para tanto, será feita uma breve descrição dos documentos para melhor delinear o corpus deste estudo, para que posteriormente, possam ser analisados os textos introdutórios e os capítulos completos desses documentos. O aporte teórico utilizado será pautado em conceitos como discurso, interdiscurso, interdiscursividade, formação discursiva, formação ideológica, relação poder-saber, formas de resistência e regimes de verdade discutidos por Foucault $(1971,2008)$, Pêcheux (1990), Mascia (2002), Bertoldo (2003), Coracini (2003), Gregolin (2004), Orlandi (2006), Veiga-Neto (2007), Possenti (2007), Amarante (2009), dentre outros.

\section{Alguns conceitos centrais da Análise do Discurso}

Para nortear este estudo, é importante retomar alguns conceitos primordiais da Análise do Discurso de linha francesa, tais como enunciado e formação discursiva. Ao tratar das relações de poder-saber, para Foucault (2000 apud SILVA, 2004), o enunciado é visto como unidade do discurso e, para investigar seu funcionamento, é necessário compreender a formação discursiva que favoreceu o aparecimento de determinados enunciados e não outros.

Conforme aponta Veiga-Neto (2007, p.94), o enunciado é um ato discursivo que se dissocia dos contextos locais e se distancia dos significados triviais do cotidiano para a constituição de um campo mais autônomo e raro de sentidos a serem "aceitos e sancionados numa rede discursiva, segundo uma ordem, seja em função do seu conteúdo de verdade, seja em função daquele que praticou a enunciação, seja em função de uma instituição que o acolhe". Essa compreensão de enunciado tem relação com as condições de produção e com as diferentes posições de quem enuncia, no caso, o sujeito. No que concerne ao conceito de formação discursiva, Foucault (1987 apud VEIGA-NETO, 2007) analisa a constituição do poder a partir das práticas discursivas e como elas produzem saberes.

Para Foucault (2008, p.43), uma formação discursiva se dá quando

[...] se puder descrever, entre um certo número de enunciados, semelhante sistema de dispersão, e no caso em que entre os objetos, os tipos de enunciação, os conceitos, as escolhas temáticas, se puder definir 
uma regularidade (uma ordem, correlações, posições e funcionamentos, transformações), diremos, por convenção, que se trata de uma formação discursiva.

Dessa maneira, conforme aponta Baronas (2004, p.55), para Foucault, a formação discursiva é tomada como um conjunto de enunciados que não podem ser reduzidos a objetos linguísticos, como proposições ou atos de fala, mas "submetidos a uma mesma regularidade e dispersão na forma de uma ideologia, ciência, teoria etc." Assim, segundo Foucault (2008), a formação discursiva caracteriza-se por sua relação com algum campo do saber.

Ao tratar de um discurso religioso, publicitário ou político-educacional, foco deste artigo, pode-se afirmar que "cada um deles compreende um conjunto de enunciados, apoiados num determinado sistema de formação ou formação discursiva", conforme afirma Fischer (2001, p.203). Os atos enunciativos se inscrevem no interior de algumas formações discursivas, segundo um determinado regime de verdade, isto é, estamos sempre obedecendo a um conjunto de regras constituído historicamente, afirmando verdades de um tempo específico.

Foucault (1997 apud GRANGEIRO, 2005), em Arqueologia do saber, considera que a noção de formação discursiva não tem relações estreitas com a ideologia, mas com os saberes e poderes, tendo como objetivo descrever os mecanismos de constituição das ciências do homem. Segundo Grangeiro (2005, p.2), para ele, "os discursos são formados por elementos que não estão ligados por nenhum princípio de unidade a priori, cabendo à Análise do Discurso descrever essa dispersão, buscando regras de formação que regem a formação dos discursos".

Foucault (2008) defende que uma formação discursiva se estabelece por meio de regularidades como ordem, correlação, funcionamento e transformação, sendo que essas regularidades determinam sua homogeneidade e fechamento (INDURSKY, 2005). Afastando-se da ideologia como princípio organizador de uma formação discursiva, Foucault (2004, p.8), em Microfísica do poder, discute algumas razões para esse distanciamento, sendo

[...] a primeira é que, queira-se ou não, ela está sempre em oposição virtual a alguma coisa que seria a verdade. Ora, creio que o problema não é de se fazer a partilha entre o que num discurso releva da cientificidade e da verdade e o que relevaria de outra coisa; mas de ver historicamente como se produzem efeitos de verdade no interior de discursos que não são em si nem verdadeiros nem falsos. Segundo inconveniente: refere-se necessariamente a alguma coisa como o sujeito. Enfim, a ideologia está em posição secundária com relação a alguma coisa que deve funcionar para ela como infraestrutura ou determinação econômica, material, etc. Por estas três razões creio que é uma noção que não deve ser utilizada sem precauções. 
Em contrapartida, o conceito de formação discursiva de Pêcheux (1990) difere da noção de Foucault (2008), pois diretamente influenciado pelas concepções althusserianas de ideologia, Pêcheux elaborou sua própria teoria do discurso, readaptando o conceito de formação discursiva de Foucault, relacionando-o à questão da ideologia e da luta de classes (GRANGEIRO, 2005).

Dessa forma, para Pêcheux (1990, p.148, tradução nossa), uma formação discursiva "determina o que pode e deve ser dito a partir de uma posição dada numa conjuntura dada." Ele ainda argumenta que "o sentido de uma palavra muda de acordo com as posições mantidas por aqueles que a empregam em função das condições pelas quais tal sequência discursiva é produzida", ou seja, tais sentidos são adquiridos de acordo com as formações ideológicas. Segundo Pêcheux (1990, p.148, tradução nossa), a formação ideológica caracteriza um elemento susceptível de intervenção, agindo

[...] como uma força em confronto com outras forças, numa conjuntura ideológica característica de uma formação social, em um dado momento; cada formação ideológica constitui assim um conjunto complexo de atitudes e de representações que não são nem individuais nem universais, mas se relacionam mais ou menos diretamente com as posições de classe em conflito umas com as outras. ${ }^{2}$

Pode-se afirmar que as formações discursivas dependem de relações presentes no interior e no exterior do discurso, enquanto as formações ideológicas se constituem nos limites entre o universal e o individual, relacionando-se às posições de classes em conflito.

Sargentini (2005, p.2), com base em Pêcheux (1990) e Robin (1977), assevera uma mudança no tratamento dos conceitos de formação discursiva e corpus, aproximando-os, pois "trata-se de pensar o espaço discursivo e ideológico onde se desenvolvem as formações discursivas em função de relações de dominação, subordinação e de contradição", ou seja, o discurso não pode mais ser visto fora das condições de produção, assim como o corpus deve ser tomado com base nessas determinadas condições de produção.

Assim, o discurso pode ser concebido como uma materialização da ideologia, pautada no materialismo histórico, e que considera que o sujeito não "decide sobre os sentidos e possibilidades de seu discurso, mas está inserido num processo

\footnotetext{
No original: "[...] qui déterminent ce qui peut et doit être dit [...] à partir d'une position donnée dans une conjoncture donnée."

2 No original: "[...] comme une force confrontée à d'autres forces, dans la conjoncture idéologique caractéristique d'une formation sociale, en un moment donné; chaque formations idéologique constitue ainsi un ensemble complexe d'attitudes et des représentations qu ni sont ni indivivuelles ni universelles, mais se rapportent plus ou moins directement à des positions des classes en conflit les unes par rapport aux autres."
} 
histórico que lhe permite determinadas inserções e não outras, ocupando um lugar social a partir do qual enuncia" (MUSSALIM, 2001 apud FOGAÇA, 2007, p. 398).

Segundo Orlandi (2006), por meio do estudo da historicidade de um texto, isto é, a forma como ele produz certos sentidos, pode-se afirmar que ele é constituído por formações discursivas diversas, reconhecido como heterogeneidade discursiva. Dessa forma, não pode ser considerado homogêneo, uma vez que é atravessado por outros discursos. Para Pêcheux (1995), um conjunto de formações discursivas, por sua vez, formaria um complexo com dominante, denominado interdiscurso, que é semelhantemente afetado pelas formações ideológicas e constituído pelo dizer já-dito.

Já na perspectiva de Foucault (1996 apud VEIGA-NETO, 2007, p.102), o discurso tem a capacidade de ativar poderes e colocá-los em circulação. Entretanto, interpretá-lo linearmente ou mecanicamente seria errôneo, pois o discurso é, simultaneamente, "instrumento e efeito de poder, e também obstáculo, escora, ponto de resistência e ponto de partida de uma estratégia oposta". O discurso seria capaz de veicular e produzir poder, utilizando o silêncio e/ou o segredo para reforçá-lo ou debilitá-lo.

Outro conceito relevante para este estudo é que se deve compreender o discurso como heterogêneo, ou seja, todo discurso é constituído por outros e dada à interdiscursividade, é impossível delimitar suas fronteiras. Para Fischer (2001, p.212), interdiscursividade é "deixar que aflorem as contradições, as diferenças, inclusive os apagamentos, os esquecimentos; enfim, significa deixar aflorar a heterogeneidade que subjaz a todo discurso", ou seja, seria a interpenetração de um discurso por outros discursos, interferindo em seu sentido.

Os conceitos acerca do discurso, interdiscurso, interdiscursividade, formação discursiva e ideológica serão retomados na discussão de outras definições pertinentes para este trabalho acerca das relações de poder-saber e as formas de resistência no discurso político-educacional apresentados na próxima seção.

\section{O discurso político-educacional e as relações de poder-saber}

Para Foucault (1971, p.15), a educação pode ser compreendida como:

[...] o instrumento graças ao qual todo o indivíduo, numa sociedade como a nossa, pode ter acesso a qualquer tipo de discurso; sabemos, no entanto, que na sua distribuição, naquilo que permite e naquilo que impede, ela segue as linhas que são marcadas pelas distâncias, pelas oposições e pelas lutas sociais. Todo o sistema de educação é uma maneira política de manter ou de modificar a apropriação dos discursos, com os saberes e os poderes que estes trazem consigo. 
Sendo assim, a educação é vista como um sistema político para manter e/ou modificar discursos por meio de seus saberes e poderes. Valendo-se dessa questão, Foucault (2008, p.122) concebe o discurso como um "conjunto de enunciados que se apóia em um mesmo sistema de formação; é assim que poderei falar do discurso clínico, do discurso econômico, do discurso da história natural, do discurso psiquiátrico".

Dada essa concepção que define determinados discursos, ao tratar do discurso político-educacional, Bertoldo (2003, p.3) o define como aquele:

[...] constituído por outras vozes, dizeres outros, advindos de formações discursivas também outras que nele se manifestam, configurando um discurso que prima, sobretudo, por afirmar sua identidade particular, qual seja, proporcionar aos professores orientações que, supostamente, seriam "aplicáveis" aos mais diversos contextos de atuação dos professores.

Segundo o autor, normalmente tais discursos são caracterizados por citações de pesquisadores em textos teóricos que respaldam os posicionamentos sobre questões relativas à Educação. De maneira semelhante, Amarante (2009, p.6) argumenta que no discurso político-educacional é possível encontrar enunciadores que "têm a delegação de falar ou agir em nome do outro, são estes que dirigem, de certa forma, o processo de apresentação e de descrição do outro". Ainda de acordo com a autora, no DPE, há uma aliança entre o poder do Estado, que atribui a si o papel de gerenciador de ações educacionais e o da tecnociência, que torna tal elo uma condição de produção de um discurso hegemônico.

Segundo Fischer (2001), Foucault compreende que cada formação discursiva é permeada por uma diversidade de relações e em cada um desses lugares ocupa uma determinada posição, dependendo das relações de poder. Extensivamente apresentado por Foucault, o poder é tido como "um conjunto difuso de micropoderes no nível cotidiano, penetrando em toda trama da sociedade ao mesmo tempo em que os saberes se organizam para atender a uma vontade de poder" (MASCIA, 2002, p.63), ou seja, não existe sociedade isenta das relações de poder. Dessa maneira, o saber não existe fora do poder, pois uma das formas de garantir ao discurso o status de verdade é por meio do saber, ou seja, o saber funciona como um elemento condutor do poder. A produção de verdade se encontra centralizada no discurso científico e nas instituições, responsáveis pela produção de saberes. Logo o sistema educacional atuaria, então, como um dispositivo social que se constitui de micromecanismos de poder, ou seja, a teoria educacional está relacionada aos fatores políticos e sociais (VEIGA-NETO, 2007).

Para Pogrebinschi (2004), Foucault discute que as bases do poder são fundamentadas em instrumentos de formação e acúmulo do saber e não nas ideologias. Foucault se ocupa do modo como o poder se exerce, compreendendo 
seus mecanismos. De acordo com a autora, o poder "se encontra em mecanismos positivos, produtores de saber, multiplicadores de discursos, indutores de prazer e geradores de mais poder" (POGREBINSCHI, 2004, p.187), ou seja, ele está em todos os lugares.

Conforme aponta Gregolin (2004), Foucault compreende o saber como conjunto de elementos regulares formados por uma prática discursiva, sendo tomada como "conjunto de regras anônimas, históricas, sempre determinadas no tempo e no espaço, que definiriam uma determinada área social, econômica, geográfica ou linguística" (FOUCAULT, 2008, p.133). Assim, o saber atribui autoridade e valor de verdade ao poder servindo-o como seu elemento condutor. Possenti (2007) discute os conceitos de saber e verdade, por meio de uma leitura de Foucault, salientando alguns cuidados na apropriação desses conceitos definidos e amplamente divulgados. O primeiro deles se refere ao saber, pois é importante compreender que ele está relacionado a uma prática, mas uma não qualquer. Segundo o autor, o saber deve ser atrelado à ciência, pois "o saber é o campo no qual se constitui um tipo de discurso que está em vias de se tornar ciência" (POSSENTI, 2007, p.12), assim como deve ser relacionado às práticas discursivas, o que Foucault (1969 apud POSSENTI, 2007) denomina eixo prática discursiva-saber-ciência. Ele considera que as verdades são produzidas por dispositivos disciplinares, segundo regimes discursivos especiais, dos saberes ou das ciências.

De acordo com Orlandi (2006, p.15), "o saber é distribuído por uma rede institucional, hierarquizada em que o saber relaciona-se ao poder." Segundo a autora, dependendo do lugar social do qual se fala, o discurso é marcado com a força da locução que tal lugar representa. A força decorrente de cada um desses lugares vem a atuar na relação de interlocução, representada nas posições sujeito, logo, tais posições nunca são neutras e estão imbuídas de poder. Ainda sobre a relação entre poder e saber, para Pogrebinschi (2004, p.199), o poder:

[...] produz; ele constrói; destrói; reconstrói; ele transforma, acrescenta, diminui, modifica a cada momento e em cada lugar a si mesmo e a cada coisa com a qual se relacione em uma rede múltipla, móvel, dinâmica, infinita ... o poder é produção em ato, é a imanência da produtividade. Acima de tudo, como vimos, o poder está em estreita relação com o saber. Poder e saber se produzem e autorreproduzem, estabelecem uma relação de mútua dependência e de mútua independência, produzindo, dessa fusão interprodutiva, um novo conceito: o poder-saber.

Segundo Foucault (2008, p.204), o saber é "aquilo de que podemos falar em uma prática discursiva que se encontra assim especificada: o domínio constituído pelos diferentes objetos que irão adquirir ou não um status científico". Logo, o 
saber vem a justificar alguns sistemas, como o penal ou o DPE, assegurando ao discurso um regime de verdade (FOUCAULT, 1971).

Conforme discute Veiga-Neto (2007, p.44), Foucault considera saberes como "teorias sistemáticas que se manifestam por meio de discursos científicos tidos por verdadeiros, positivos, e por isso, aceitos e tomados em toda sua positividade". Compreendido dessa maneira, esses saberes não são produzidos pelos sujeitos, uma vez que eles são produzidos no interior de saberes. Por exemplo, a própria escola pode ser vista como um mecanismo de produção de corpos dóceis, por meio da ação do poder disciplinar que se instaura nessas instituições, cumprindo um papel primordial para a constituição da sociedade moderna.

De acordo com Silva (2004), é por meio do poder disciplinar que se pode explicar o mecanismo de funcionamento do poder sobre os indivíduos. Pode-se afirmar que o poder disciplina o homem, logo, ele pode ser considerado uma produção do poder e objeto do saber. Segundo Machado (1979 apud SILVA, 2004, p.173), a ação da disciplina pode atuar nas instituições de ensino por intermédio da "distribuição espacial, controle do tempo, aprendizagem progressiva, maximização das habilidades que quando aplicadas aos corpos, possibilitam a formulação de saberes sobre o homem na sociedade moderna".

Com base nos estudos de Foucault (2004), Mascia (2002) afirma que o poder está presente em toda a trama de uma sociedade, mas ele em si não é visível e nem existe, o que se tem são práticas e relações de poder. Logo se entende que o próprio sistema educacional atuaria como um dispositivo social que é constituído por micromecanismos de poder.

Uma vez que, segundo Foucault (1984 apud MASCIA, 2002), não há sociedade sem relações de poder, o poder atuaria em nossos corpos, não como algo que emana de um centro (uma instituição ou o Estado), pois está pulverizado na sociedade e se exerce no Estado, não deriva dele, pois o poder existe em meio às práticas em que ele se manifesta. Nessa rede, o saber é responsável por conduzir o poder.

Nessa perspectiva, o poder existe e funciona em meio a uma rede, em que há pontos de resistência ao poder, no entanto, não se deve conceber a resistência como uma antítese ao poder (VEIGA-NETO, 2007). Ainda de acordo com o referido autor, Foucault (1993 apud VEIGA-NETO, 2007) não considera o conhecimento como uma faculdade inerente ao ser humano, pois o toma como um acontecimento articulado com o poder. Para Foucault (1993 apud VEIGA-NETO, 2007), o saber é uma construção histórica, dessa maneira, que produz suas verdades e seus regimes de verdade, que simultaneamente se instauram e se revelam nas práticas discursivas e não-discursivas. Dessa forma, "as relações de força constituem o 
poder, ao passo que as relações de forma constituem o saber" (VEIGA-NETO, 2007, p.129-130).

Pode-se assumir que o saber alimenta o poder, pois atribui a ele um valor de verdade. Em Microfísica do poder, Foucault (2004, p.11) comenta sobre essa relação e afirma que a verdade é:

[...] centrada na forma do discurso científico e nas instituições que o produzem; está submetida a uma constante incitação econômica e política (necessidade de verdade tanto para a produção econômica, quanto para o poder político); é objeto, de várias formas, de uma imensa difusão e de um imenso consumo (circula nos aparelhos de educação ou de informação, cuja extensão no corpo social é relativamente grande, não obstante algumas limitações rigorosas); é produzida e transmitida sob o controle, não exclusivo, mas dominante, de alguns grandes aparelhos políticos ou econômicos (universidade, exército, escritura, meios de comunicação); enfim, é objeto de debate político e de confronto social (as lutas "ideológicas").

Para Foucault (1984 apud MASCIA, 2002), a verdade se encontra centralizada no discurso científico e é também produzida sob o controle dominante de instituições políticas e/ou econômicas, logo seu valor e seu sentido se encontram em relação a um dado momento histórico-social. As relações entre verdade e poder são simbólicas, uma vez que a verdade e/ou seus efeitos estão atrelados a sistemas de poder, produzindo regimes de verdade por meio de mecanismos discursivos no interior dos discursos.

Tomando como base essas questões, é preciso assumir que onde há poder, emergem formas de resistência. Assim, para Foucault (2006), ele é localizado no discurso e, ao mesmo tempo, é instrumento e efeito de poder, sendo veiculador e produtor de poder. E o discurso é o lugar em que o poder é exercido e lugar de resistência do sujeito ao mesmo poder, pois suas relações sustentam a possibilidade de resistência, configurando uma luta perpétua e multiforme. Essa compreensão acerca das formas de resistência corrobora o argumento de De Certeau (1988 apud MASCIA, 2002), de que a linguagem teria como propriedades carregar um poder de resistência, pois não há poder sem resistência, e a de deixar emergir, retomando o que fora eliminado.

Essas relações de poder-saber, seu regime de verdade e as formas de resistência serão focalizados na análise e discussão dos pressupostos das Orientações Curriculares para o Ensino Médio e da Proposta Curricular do Estado de São Paulo, para tanto, na seção a seguir será feita uma breve descrição do corpus utilizado neste estudo. 


\section{Descrição do corpus}

De acordo com Orlandi (2006), a Análise do Discurso se ocupa do texto, tomando-o como unidade, procurando trabalhar com sua discursividade, como ele produz sentido, qual seu funcionamento e como se dá sua exterioridade.

Pautando-se nessa premissa, neste artigo, tomaremos como objeto discursivo as Orientações Curriculares Nacionais para o Ensino Médio (2006) e a Proposta Curricular do Estado de São Paulo: Língua Estrangeira Moderna (2008). O primeiro deles foi elaborado pela Secretaria de Educação Básica (SEB) e é constituído por três volumes, cada um deles reservado a uma área de conhecimento distinta. Tais Orientações têm como principal objetivo favorecer o diálogo entre professor e escola no que se refere à prática docente.

Nas Orientações Curriculares para o Ensino Médio, o capítulo referente aos "Conhecimentos de línguas estrangeiras" visa a elucidar reflexões acerca do ensino e aprendizagem de língua estrangeira, focalizando a leitura, a prática escrita e a comunicação oral, fundamentando-se em questões como senso de cidadania, inclusão social/digital e cultura local e global. Além dessas questões, o documento objetiva difundir e explicitar propostas de atividades pautadas nas teorias de letramento, multiletramento, multimodalidade e hipertexto entre os professores da rede pública.

Para os propósitos deste trabalho, apenas o volume destinado a Linguagens, códigos e suas tecnologias, especificamente o capítulo 3. "Conhecimentos de línguas estrangeiras" será discutido, assim como a "Carta ao professor" e a "Apresentação" ao início do documento.

Além das Orientações Curriculares, a Proposta Curricular do Estado de São Paulo: Língua Estrangeira Moderna - Inglês, a "Carta da secretaria" e a "Apresentação" da proposta, documentos elaborados em 2008 pela Secretaria de Educação do Estado de São Paulo também serão utilizados para a análise. Com a Proposta Curricular a Secretaria do Estado de São Paulo (SEE) pretende "cumprir seu dever de garantir a todos uma base comum de conhecimentos e competências, para que nossas escolas funcionem de fato como uma rede" (SÃO PAULO, 2008, p.8). No que se refere às especificidades em relação ao ensino de língua estrangeira, o documento prevê que o ensino da língua-alvo seja pautado pela noção de letramento a fim de propiciar uma "visão de ensino de línguas que seja capaz de promover autonomia intelectual e maior capacidade de reflexão dos aprendizes, contribuindo decisivamente para a formação cidadã dos educandos" (SÃO PAULO, 2008, p.42).

Na seção seguinte, tem-se a análise de tais documentos pautada no pressuposto de que as relações de poder-saber e as formas de resistência a esse 
poder encontram-se presentes no DPE e nas práticas discursivas por meio das quais os regimes de verdade são construídos.

\section{Reflexões sobre os documentos oficiais e as relações de poder-saber}

A "Carta ao professor", elaborada pelo Ministério da Educação e pela Secretaria de Educação Básica, introduz as Orientações Curriculares. Nela, revelam-se estratégias de manutenção do poder no sentido de persuadir o sujeitoleitor (professor) a contribuir para a propagação de interesses comuns, remetendo à coletividade e visando à melhoria da qualidade de ensino (MASCIA, 2002), como pode ser constado em:

Excerto 1: "Carta ao professor".

A qualidade da escola é condição essencial de inclusão e democratização das oportunidades no Brasil, e o desafio de oferecer uma educação básica de qualidade para a inserção do aluno, o desenvolvimento do país e a consolidação da cidadania é tarefa de todos. (BRASIL, 2006, p.5).

Além disso, por meio da autoria delegada ao Ministério da Educação e à Secretaria de Educação Básica, há representação do poder mantida pela instituição, exercida pelo Estado, denotando suas relações de força. Conforme aponta Orlandi (2006, p.16) "o lugar social do qual falamos marca o discurso com a força da locução que este lugar representa", dessa forma, o discurso da "Carta" imbui-se do poder em suas relações de força. No excerto seguinte da "Carta", tem-se a ilusão de garantia da construção democrática do documento, remetendo à noção de construção coletiva, como se apresenta a seguir:

Excerto2: "Carta ao professor".

As Orientações Curriculares para o Ensino Médio foram elaboradas a partir de ampla discussão com as equipes técnicas dos Sistemas Estaduais de Educação, professores e alunos da rede pública e representantes da comunidade acadêmica. (BRASIL, 2006, p.5).

A noção de processo de construção democrática realiza-se no excerto por meio do apagamento de um sujeito único e da ocorrência de um sujeito coletivizado, constatado também na pesquisa de Mascia (2002) sobre a análise de documentos norteadores da educação em língua estrangeira. O mesmo ocorre no texto de "Apresentação" das Orientações, elaborado pela Coordenação Geral de Ensino Médio e Diretoria de Concepções e Orientações Curriculares para a Educação Básica, que segue uma dada hierarquia de classe historicamente construída. 
Na "Apresentação", a ideia de processo de construção democrática se revela por meio de trechos que destacam a participação de diferentes agentes pertencentes à esfera educacional, como pode ser observado em:

Excerto 3: "Apresentação".

A elaboração das reflexões que o Ministério da Educação traz aos professores iniciou em 2004. Desde então, definiu-se um encaminhamento de trabalho que garantisse a articulação de representações da universidade, das Secretarias Estaduais de Educação e dos professores para alcançar uma produção final que respondesse a necessidades reais da relação de ensino e aprendizagem. (BRASIL, 2006, p.8).

Observa-se, no excerto seguinte, que a Coordenação Geral de Ensino Médio e Diretoria de Concepções e Orientações Curriculares para a Educação Básica, representando o Estado, delegam a responsabilidade pela autoria do material e o controle da qualidade das propostas apresentadas ao "grupo de pesquisadores":

Excerto 4: "Apresentação".

Para dar partida a essa tarefa, constitui-se um grupo de trabalho multidisciplinar com professores que atuam em linhas de pesquisa voltadas para o ensino [...]. Na elaboração de material específico para cada disciplina do currículo do ensino médio, o grupo procurou estabelecer o diálogo necessário para garantir a articulação entre as mesmas áreas de conhecimento. (BRASIL, 2006, p.8).

O trecho, entretanto, não deixa claro ao leitor como esse grupo foi estabelecido (quem o definiu, quem eram os participantes, como foram escolhidos), mas se subentende que ele fora apontado por instâncias governamentais, logo representam o poder do Estado, assegurado pelo saber advindo do status científico dos pesquisadores, atribuindo valor de verdade ao documento (FOUCAULT, 2008; POSSENTI, 2007). Além disso, como a autoria do documento foi atribuída ao grupo de pesquisadores, cujo poder-saber é socialmente reconhecido e amplamente aceito como verdade, pode-se afirmar que há uma representação do poder exercido pelo governo, conduzido por meio do saber institucionalizado, como argumentam Foucault (1971), Mascia (2002) e Veiga-Neto (2007).

Nas Orientações Curriculares para o Ensino Médio: Linguagens, Códigos e suas Tecnologias, o capítulo referente aos "Conhecimentos de línguas estrangeiras" faz uso de estratégias retórico-argumentativas comuns ao discurso científico como a recorrência de citações de pesquisadores, que no DPE, podem ocorrer como uma intenção de convencer o leitor (professor) do valor de verdade do documento, como pode ser constatado no seguinte excerto: 
Paralelamente ao fato de haver mais ocorrência do gênero crônica em português do que em inglês, podem-se apreciar também as formas diferentes que a escrita, como prática sociocultural, adquire numa mesma língua ou numa mesma cultura: diversos estudos (GEE, 2000) mostram como grupos sociais diferentes, numa mesma cultura, usam materiais escritos de formas diferentes, em diferentes conjuntos de habilidades de linguagem. (BRASIL, 2006, p.100).

O emprego dessas estratégias do discurso científico parte do pressuposto de que o professor da rede pública é conhecedor da matéria, daquilo que se diz e da forma como se diz (MASCIA, 2002). As relações de força e regimes de verdade, presentes no DPE, reforçam os argumentos de Foucault (1971) e Amarante (2009) de que os enunciadores devem falar ou agir em nome do outro, uma vez que a teoria educacional está atrelada a fatores políticos e sociais. Assim sendo, o sistema educacional é visto como um dispositivo social que se constitui de micromecanismos de poder, mantidos pelo saber que o justifica e o mantém.

Outro ponto que merece destaque em tais documentos é a presença de sugestões de atividades para o ensino de LE, segundo as teorias de letramento, como pode ser visto nos excertos seguintes:

Excerto 6.

[...] o exercício de leitura desse texto deve, segundo as teorias de letramento, desenvolver/voltar-se para a habilidade de construção de sentidos, inclusive a partir de informações que não constam no texto. Poderia, por exemplo, prever perguntas ou reflexões como: quais são os possíveis significados e leituras a serem construídos a partir desse texto? Quem são os brasileiros descritos no texto como usuários de internet? (BRASIL, 2006, p.93)

Excerto 7.

Quadro 1 - Sugestão de planejamento para desenvolvimento de leitura

\begin{tabular}{|l|l|}
\hline \multicolumn{1}{|c|}{ TEMA } & \multicolumn{1}{c|}{ INCLUSÃO/EXCLUSÃO } \\
\hline Tipo de Texto & Artigo de internet \\
\hline Escolha do Assunto & Acesso à informática (exemplo da p.93) \\
\hline
\end{tabular}




\begin{tabular}{|c|c|}
\hline TEMA & INCLUSÃO/EXCLUSÃO \\
\hline Letramento Crítico & $\begin{array}{l}\text { (exemplo da p.93) } \\
\text { Quais são os possíveis significados e leituras a serem } \\
\text { construídos a partir desse texto? } \\
\text { Quem são os brasileiros descritos no texto como usuários da } \\
\text { Internet? Quem não está incluído nessa estatística e por quê? } \\
\text { O que é necessário para ser um bom usuário da internet? }\end{array}$ \\
\hline Leitura Crítica & $\begin{array}{l}\text { (exemplo da p.93) } \\
\text { A quem o texto se dirige? } \\
\text { Que recursos gráficos são utilizados para realçar certas } \\
\text { informações no texto? } \\
\text { A que se referem os números mencionados no texto? }\end{array}$ \\
\hline $\begin{array}{l}\text { reensão } \\
\text { al }\end{array}$ & $\begin{array}{l}\text { Compreensão geral dos pontos principais e das informações } \\
\text { detalhadas do texto. }\end{array}$ \\
\hline $\begin{array}{l}\text { Aspectos } \\
\text { Linguísticos } \\
\text { (a serem focalizados por } \\
\text { meio de textos variados, } \\
\text { ao longo dos três anos } \\
\text { do ensino médio) }\end{array}$ & $\begin{array}{l}\text { Conteúdos linguístico-textuais } \\
\text { Cognatos } \\
\text { Grupos nominais } \\
\text { Prefixos } \\
\text { Sufixos } \\
\text { Referência textual } \\
\text { Inferência lexical } \\
\text { Tempos e formas verbais } \\
\text { Categorias de palavras (substantivos, adjetivos, advérbios, por } \\
\text { exemplo) } \\
\text { Estrutura passiva } \\
\text { Elementos de ligação }\end{array}$ \\
\hline
\end{tabular}

Fonte: Brasil (2006, p.117-118).

Nota-se que no excerto 6, retirado da página 93, no trecho "segundo as teorias de letramento", há uma tentativa de assegurar o valor de verdade daquilo que se profere por meio do discurso científico, muito embora, as definições pormenorizadas de letramento sejam apresentadas ao leitor mais adiante nos documentos (p.98), na seção destinada exclusivamente à definição do conceito de letramento. A apresentação das teorias de letramento é feita como uma abordagem pertinente para a otimização do desenvolvimento de atividades de leitura, o que permite sua sustentação pelo regime de verdade (BERTOLDO, 2003).

No excerto 7, a apresentação do quadro pode vir a contribuir para a atribuição de um tom prescritivo ao propor o conteúdo textual, lexical, e gramatical a ser 
desenvolvido ao longo dos três anos do Ensino Médio e por meio das sugestões de atividades de leitura voltadas para o letramento. Tendo em mente as seções "Leitura Crítica" e "Letramento Crítico" presentes no quadro 1 (excerto 7), Coracini (2003) argumenta sobre a recorrência do termo consciência crítica em estudos no âmbito educacional, e questiona o real significado do termo atrelado à leitura crítica, comumente proposto em programas escolares, como nas Orientações. Segundo a autora (CORACINI, 2003, p.272), leitura crítica "significa perceber as intenções do autor, ser capaz de discutir suas ideias, interpretar (não apenas compreender), perceber a polifonia do texto, envolver-se ativamente no processo de leitura, enfim, criticar as ideias por ele veiculadas". Essa noção está permeada na visão de leitura abarcada no quadro com sugestões de atividades apresentados anteriormente (excerto 7), assim como no trecho a seguir:

Excerto 8.

Trata-se da adoção das teorias de letramentos e multiletramentos, sobre as quais nos detivemos anteriormente. Essas teorias funcionam como base educacional e epistemológica. Ou seja, poderão contribuir para ampliar a visão de mundo dos alunos, para trabalhar o senso de cidadania, para desenvolver a capacidade crítica, para construir conhecimento em uma concepção epistemológica contemporânea. [...] o trabalho de leitura que utiliza textos não autênticos, ou seja, aqueles construídos com tempos verbais limitados a um conhecimento estrutural e gradativo, isto é, que narram ou descrevem somente o tempo presente ou só o passado, denotando uma narrativa artificial [...], trata-se de uma concepção antiga, que não mais condiz com o trabalho de leitura que pretende formar leitores independentes e críticos. (BRASIL, 2006, p.112-113).

Não obstante, o excerto 8 assegura a construção de conhecimento pautada numa concepção contemporânea, como ideia de inovação no cenário educacional em detrimento de outras abordagens de ensino (de base estruturalista) dado o contexto histórico-social atual (MASCIA, 2002).

Em contrapartida, na Proposta Curricular do Estado de São Paulo para o ensino de língua estrangeira moderna - inglês no ciclo II do ensino fundamental e ensino médio, elaborado em 2008 pela Secretaria de Educação do Estado de São Paulo (SEE), observam-se algumas manifestações de resistência (MASCIA, 2002) ao que se prevê nas Orientações Curriculares (BRASIL, 2006).

A Proposta Curricularé introduzida pela "Carta da Secretária", que contraria a perspectiva de diálogo com as secretarias estaduais para a construção coletiva das Orientações Curriculares (2006), também mencionadas anteriormente na "Carta ao professor" e na "Apresentação", devido às visões divergentes com relação ao sistema escolar, como pode ser visto em: 
Excerto 9: "Carta da Secretária".

A criação da Lei de Diretrizes e Bases (LDB), que deu autonomia às escolas para que definissem seus próprios projetos pedagógicos, foi um passo importante. Ao longo do tempo, porém, essa tática descentralizada mostrou-se ineficiente. Por esse motivo, propomos agora uma ação integrada e articulada, cujo objetivo é organizar melhor o sistema educacional de São Paulo. (SÃO PAULO, 2008, p.5).

Segundo Foucault (2004, p.10), a sociedade tem seu regime de verdade próprio e por meio dela os discursos são tomados como verdadeiros, permitindo aos mecanismos e as instâncias "distinguir os enunciados verdadeiros dos falsos" e decidindo "técnicas e procedimentos que são valorizados para a obtenção da verdade; o estatuto daqueles que têm o encargo de dizer o que funciona como verdadeiro". Pode-se afirmar que a SEE, como instância representante do governo estadual, faz uso de técnicas e procedimentos para valorização do que considera verdadeiro, ao assumir que a Lei de Diretrizes e Bases não foi eficiente e que a Proposta Curricular visa articular e organizar o ensino no estado de São Paulo. A visão sobre a LDB trazida pela SEE difere daquela presente nas Orientações Curriculares, pois, nelas, a lei é vista da seguinte maneira:

Excerto 10: "Apresentação".

Os atuais marcos legais para a oferta do ensino médio, consubstanciados na Lei de Diretrizes e Bases da Educação Nacional (n॰ 9394/96), representam um divisor na construção da identidade da terceira etapa da educação básica brasileira. [...] O grande avanço determinado por tais diretrizes consiste na possibilidade objetiva de pensar a escola a partir de sua própria realidade, privilegiando o trabalho coletivo. Ao se tratar da organização curricular tem-se a consciência de que a essência da organização escolar é, pois, contemplada. (BRASIL, 2006, p.7).

Considerando que o discurso é o lugar em que o poder é exercido e contexto de resistência do sujeito a esse mesmo poder, pode-se inferir que há uma manifestação de resistência da Secretaria de Educação do Estado de São Paulo (Proposta Curricular) frente ao poder da Secretaria de Educação Básica (Orientações Curriculares), o que corrobora o argumento de Foucault (2006), de que as relações de poder possibilitam a resistência ao poder daquele que domina e tenta se manter.

Tratando mais especificamente do processo de ensino e aprendizagem de língua inglesa, os dois documentos são norteados pelas concepções de letramento e multiletramento. Os pontos de convergência entre as Orientações Curriculares e a Proposta Curricular se referem também aos aspectos relacionados à inclusão 
social e digital, acesso ao conhecimento e informação, desenvolvimento da autonomia e da cidadania do aprendiz. Entretanto, o objetivo do ensino de língua estrangeira nas Orientações Curriculares é priorizar a leitura, a prática escrita e a comunicação oral de maneira contextualizada. Já no que tange à Proposta Curricular, o que se nota é:

Excerto 11: "Apresentação".

[...] em virtude da centralidade da linguagem no desenvolvimento da criança e do adolescente que esta Proposta Curricular prioriza a competência leitora e escritora. Só por meio dela será possível concretizar a constituição das demais competências, tanto as gerais como aquelas associadas a disciplinas ou temas específicos. (SÃO PAULO, 2008, p.18).

Além disso, na Proposta Curricular, observa-se presença de sugestões de conteúdos e habilidades para o ensino de LE para os quatro bimestres desde a quinta série do ensino fundamental até a terceira série do ensino médio, conforme o seguinte excerto:

Excerto 12.

Quadro 2 - Proposta curricular para LEM - Língua Inglesa Ensino fundamental - Ciclo II

\begin{tabular}{|c|c|}
\hline \multicolumn{2}{|c|}{$\begin{array}{l}5^{\mathbf{a}} \text { Série } \\
\text { Aquisição de repertório lexical e reconhecimento de estruturas }\end{array}$} \\
\hline $1^{\circ}$ Bimestre & $2^{\circ}$ Bimestre \\
\hline $\begin{array}{l}\text { Primeiros contatos } \\
\text { Cumprimentos e despedidas } \\
\text { Identificação pessoal: nome, idade, endere- } \\
\text { ço e telefone. } \\
\text { Número em língua inglesa } \\
\text { Gêneros para leitura e escrita } \\
\text { Fichas de cadastro e formulários (identifi- } \\
\text { cação de dados) } \\
\text { Produção: cartão de identificação escolar }\end{array}$ & $\begin{array}{l}\text { As línguas estrangeiras em nosso entorno } \\
\text { Reconhecimento de palavras estrangeiras } \\
\text { em nomes de lugares, marcas de produtos, } \\
\text { equipamentos, jogos, internet etc. } \\
\text { Análise de palavras estrangeiras presentes } \\
\text { no cotidiano, sua origem e adaptação em } \\
\text { língua materna. } \\
\text { Gêneros para leitura e escrita } \\
\text { Leitura de portadores de textos impressos } \\
\text { que tenham palavras estrangeiras (cami- } \\
\text { setas, embalagens, manuais, cartões de } \\
\text { jogos). } \\
\text { Produção: pôsteres sobre a presença da } \\
\text { língua inglesa no cotidiano. }\end{array}$ \\
\hline
\end{tabular}

Fonte: São Paulo (2008, p.45). 
O quadro de conteúdos e habilidades a serem desenvolvidas na escola pode vir a contribuir para a atribuição de um valor prescritivo ao documento da Secretaria de Educação do Estado de São Paulo, uma vez que atrelado a esse fato, juntamente com a Proposta Curricular, a SEE encaminhou às escolas, os Cadernos do Professor que abordam tais conteúdos por meio de sugestões de atividades e avaliações, a serem implementadas pelos professores em suas salas de aula.

Ao retomar os trabalhos de Foucault $(1971,1977,2008)$ para pensar sobre as relações de poder pressupõe-se que onde há poder, há formas de resistência. Os documentos oficiais advindos de instâncias federais e estaduais, a SEB e a SEE, tem como premissa dar orientações e norteamentos para a melhoria dos processos de ensino e aprendizagem. Para tanto, utilizam o saber como forma de atrelar ao discurso um caráter de verdade. No entanto, esses documentos também pressupõem que os professores, sujeitos a esse poder-saber veiculado no DPE, aderem a essas propostas de forma engajada, sem conflitos, dado o status científico, tomado como verdade. Celani (2010) igualmente questiona a implementação desses documentos educacionais oficiais, pois sua mera distribuição não garante que esses documentos sejam compreendidos, aceitos e aplicados na prática pelos professores nas escolas. Sabe-se que essas relações não ocorrem sem embates, assim como foi possível observar ao confrontar as Orientações Curriculares (2006) e a Proposta Curricular (2008).

\section{Considerações finais}

Por meio da análise das Orientações Curriculares Nacionais para o Ensino Médio e da Proposta Curricular do Estado de São Paulo, nota-se que os traços argumentativos constituintes de tais documentos contribuem para o estabelecimento de um regime de verdade, perpassado por relações de podersaber. O regime de verdade é assegurado no Discurso Político-Educacional pelas inúmeras referências e citações de pesquisas de especialistas na área de ensino e aprendizagem de línguas ou da Educação, atribuindo o valor de verdade por meio do status científico do saber institucionalizado, que não é advindo do Estado, mas é mantido por ele (FOUCAULT, 1971; VEIGA-NETO, 2007; POSSENTI, 2007).

Nas Orientações Curriculares, as relações entre o saber e o poder ocorrem como uma via de mão dupla, pois o uso da voz de pesquisadores e especialistas envolve o saber científico e acadêmico por eles produzidos, o que, simultaneamente, assegura e alimenta as relações de poder do Estado sobre o sistema educacional, levando em consideração o lugar ocupado por tais pesquisadores no discurso. Ao comparar esse documento à Proposta Curricular, nota-se que o documento do estado de São Paulo deixa transparecer formas de resistência ao que é tido como verdadeiro pela SEB, por meio das divergências presentes no documento. Há um 
apagamento da "voz" das Orientações Curriculares devido à incompatibilidade com as necessidades do sistema educacional de São Paulo, como pode ser visto na Proposta Curricular. Outra questão relevante é acerca do fato que de tais documentos foram publicados em 2006 e 2008, colocando professores em meio aos enfrentamentos teóricos e metodológicos das duas instâncias governamentais.

Os documentos ainda pressupõem a conscientização dos alunos por meio das teorias de letramento crítico. Entretanto, segundo as perspectivas advindas da Análise do Discurso de linha francesa, deve-se ter em mente que o sujeito marcado pela incompletude, não decide sobre os sentidos de seu dizer, pois é incapaz de transformar o mundo conscientemente, nunca é dono de si, é simultaneamente livre e submisso. Dado seu caráter contraditório, pode transformar o mundo a sua volta, mas nunca terá controle total sobre as tais transformações (FOGAÇA, 2007; ORLANDI, 2006; BERTOLDO, 2005; MASCIA, 2002; PÊCHEUX, 1995).

No entanto, o ato de atingir tais transformações é o que alimenta e estimula pesquisadores e professores na eterna busca pela compreensão de si e do mundo. Os próprios autores das Orientações Curriculares (BRASIL, 2006, p.98) mencionam que "as teorias educacionais subjacentes às orientações neste documento não pretendem negar a presença de conflitos", mas compreender que eles existem e que fazem parte da complexidade das relações sociais.

\section{Agradecimentos}

Gostaria de agradecer à Profa. Dra. Vanice Maria Oliveira Sargentini pela leitura criteriosa, bem como pelas contribuições teóricas e sugestões incorporadas neste trabalho. As falhas remanescentes são de minha inteira responsabilidade.

KANEKO-MARQUES, S. M. Power-knowledge relation and resistance forms in government educational documents on foreign language teaching. Alfa, v.56, n.1, p.271-292, 2012.

- ABSTRACT: Considering political-educational discourse as a context for power manifestation, this study goal explores the power-knowledge relationship in official educational documents in different government instances where forms of resistance can be spotted. To verify how this relationship is established, two specific curricular documents are analyzed: Orientações Curriculares para o Ensino Médio: Linguagens, Códigos e suas Tecnologias (2006), the official curriculum orientations issued by the Basic Education Department (Secretaria de Educação Básica - SEB), and Proposta Curricular do Estado de São Paulo: Língua Estrangeira ModernaInglês (2008), the official curriculum proposal issued by the Department of Education of São Paulo State (Secretaria da Educação de São Paulo - SEE). This study theoretical framework deals with the following concepts: power-knowledge relations, forms of resistance, and truth regimes largely discussed by Foucault (1971, 2008), Pêcheux (1990), Mascia (2002), Bertoldo (2003), Coracini (2003), Gregolin (2004), Orlandi (2006), Veiga-Neto (2007), Possenti (2007), 
and Amarante (2009). The analysis of the documents reveals some of their argumentative traces that contribute to the establishment of a truth regime influenced by power-knowledge relations. Moreover, results point out conflicting issues between the Curriculum Orientations and the Curriculum Proposal concerning theoretical presuppositions and practical guidelines to language teaching and learning.

- KEYWORDS: Teaching. Foreign language. Power-knowledgerRelation. Political-educational discourse.

\section{REFERÊNCIAS}

AMARANTE, M. F. S. Representações de poder: (in)verdades no discurso político educacional sobre educação a distância. In: CONGRESSO INTERNACIONAL DA ABRAPUI, 2., 2009, Cedral, SP. Anais... São José do Rio Preto: Ed. da UNESP, 2009. p.1-18.

BARONAS, R. L. Formação discursiva em Pêcheux e Foucault: uma estranha paternidade. In: SARGENTINI, V. M. O.; NAVARRO-BARBOSA, P. L. (Org.). Foucault e os domínios da linguagem: discurso, poder e subjetividade. São Carlos: Claraluz, 2004. p.45-62.

BERTOLDO, E. S. O discurso pedagógico da linguística aplicada. In: CORACINI, M. J. R. F; BERTOLDO, E. S. (Org.). O desejo da teoria e a contingência da prática: discursos sobre e na sala de aula de língua materna e estrangeira. Campinas: Mercado das Letras, 2003. p.161-189.

Políticas de formação de professores de língua e seu impacto no sujeitoprofessor. In: SEMINÁRIO DE ESTUDOS EM ANÁLISE DO DISCURSO-SEAD, 2., 2005, Porto Alegre. Anais.... Porto Alegre: UFRGS, 2005. Disponível em:

$<$ http://www.discurso.ufrgs.br/sead2/doc/sujeito/ernesto.pdf>. Acesso em: 24 jan. 2011.

BRASIL. Ministério da Educação. Secretaria de Educação Básica. Orientações curriculares para o ensino médio. Linguagens, códigos e suas tecnologias. v.1. Brasília, 2006. Disponível em: <http://portal.mec.gov.br/seb/arquivos/pdf/ book_volume_01_internet.pdf>. Acesso em: 17 out. 2011.

CELANI, M. A. A. Perguntas ainda sem respostas na formação de professores de línguas. In: GIMENEZ, T.; MONTEIRO, M.C.G. Formação de professores de línguas na América Latina e transformação social. Campinas: Pontes, 2010. p.57-67.

CORACINI, M. J. R. F. A consciência crítica nos discursos sobre a e da sala de aula. In: CORACINI, M. J. R. F; BERTOLDO, E. S. (Org.). O desejo da teoria e a contingência da prática: discursos sobre e na sala de aula de língua materna e estrangeira. Campinas: Mercado das Letras, 2003. p.271-289. 
FISCHER, R. M. B. Foucault e a análise do discurso em educação. Cadernos de Pesquisa, São Paulo, n.114, p.197-223, 2001.

FOGAÇA, F. C. Formações discursivas polêmicas nos bastidores dos debates sobre educação. Linguagem e Ensino, Pelotas, v.10, n.2, p.395-413, 2007.

FOUCAULT, M. A arqueologia do saber. Tradução de Luís Felipe Baeta Neves. 7.ed. Rio de Janeiro: Forense Universitária, 2008.

Poder e saber. Entrevista gravada em Paris, em 13 de outubro de 1977. In: MOTTA, M. B. (Org). Michel Foucault: estratégia, poder-saber. 2.ed. Rio de Janeiro: Forense Universitária, 2006. p.223-240. (Ditos e escritos).

Microfísica do poder. 20.ed. Tradução de Luiz Felipe Baeta Neves. Rio de Janeiro: Graal, 2004.

A ordem do discurso. Tradução de Edmundo Cordeiro e António Bento.

Paris:

Éditions Gallimard, 1971. p.1-29. Disponível em

<http://vsites.unb.br/fe/tef/filoesco/foucault/ordem.pdf>. Acesso em: 25 jan. 2011.

GRANGEIRO, C. R. P. A propósito do conceito de formação discursiva em Michel Foucault e Michel Pêcheux. In: SEMINÁRIO DE ESTUDOS EM ANÁLISE DO DISCURSO-SEAD, 2., Porto Alegre, 2005. Anais... Porto Alegre:UFRGS, 2005. p.1-8. Disponível em: <http://www.discurso.ufrgs.br/sead2/doc/claudiagrangeiro.pdf>. Acesso em: 24 jan. 2011.

GREGOLIN, M. R. V. Foucault e Pêcheux na análise do discurso: diálogos e duelos. São Carlos: Claraluz, 2004.

INDURSKY, F. Formação discursiva: ela ainda merece que lutemos por ela? In: SEMINÁRIO DE ESTUDOS EM ANÁLISE DO DISCURSO-SEAD, 2., Porto Alegre, 2005. Anais... Porto Alegre: UFRGS, 2005. p.1-11. Disponível em:

<http://www.discurso.ufrgs.br/sead2/doc/freda.pdf>. Acesso em: 24 jan. 2011.

MASCIA, M. A. A. Investigações discursivas na pós-modernidade: uma análise das relações poder-saber do discurso político-educacional de língua estrangeira. Campinas: Mercado das Letras, 2002.

ORLANDI, E. P. Análise do discurso. In: ORLANDI, E. P.; LAGAZZI-RODRIGUES, S. (Org.). Introdução às ciências da linguagem: discurso e textualidade. Campinas: Pontes, 2006. p.11-31.

PÊCHEUX, M. La sémantique et le coupure saussurienne: langue, langage, discours. In: L'inquietude du discours. Textes de Michel Pêcheux choisis et presentés par Denise Maldidier. Paris: Cendres, 1990. 
. Semântica e discurso: uma crítica à afirmação do óbvio. Campinas: Ed. da UNICAMP, 1995.

POGREBINSCHI, T. Foucault, para além do poder disciplinar e do biopoder. Lua Nova: Revista de Cultura e Política, n.63, p.179-201, 2004.

POSSENTI, S. Sobre dois conceitos de Foucault. Revista do GEL, São José do Rio Preto, v.4, n.2, p.11-22, 2007.

ROBIN, R. História e linguística. São Paulo: Cultrix, 1977.

SÃO PAULO. Secretaria de Educação. Proposta Curricular do Estado de São Paulo. São Paulo: SEE, 2008. Disponível em:

<http://www.rededosaber.sp.gov.br/portais/Portals/18/arquivos/Prop_LEM_ COMP_red_md_20_03.pdf >. Acesso em: 10 jan. 2011.

SARGENTINI, V. M. O. A noção de formação discursiva: uma relação estrita com o corpus na análise do discurso. In: SEMINÁRIO DE ESTUDOS EM ANÁLISE DO DISCURSO-SEAD, 2., Porto Alegre, 2005. Anais... Porto Alegre:UFRGS, 2005. p.1-6. Disponível em: <http://www.discurso.ufrgs.br/sead2/doc/vanicesargentini.pdf>. Acesso em: 24 jan. 2011.

SILVA, F. P. Articulações entre poder e discurso em Michel Foucault. In: SARGENTINI, V. M. O.; NAVARRO-BARBOSA, P. L. (Org.). Foucault e os domínios da linguagem: discurso, poder e subjetividade. São Carlos: Claraluz, 2004. p.159179.

VEIGA-NETO, A. Foucault e a educação. 2.ed. Belo Horizonte: Autêntica, 2007.

Recebido em agosto de 2011.

Aprovado em outubro de 2011. 